\title{
Perioperative management of classic bladder exstrophy
}

This article was published in the following Dove Press journal:

Research and Reports in Urology

II March 2013

Number of times this article has been viewed

\author{
Eric Z Massanyi' \\ John P Gearhart' \\ Sabine Kost-Byerly ${ }^{2}$ \\ 'Division of Pediatric Urology, \\ Department of Urology, James \\ Buchanan Brady Urological Institute, \\ ${ }^{2}$ Division of Pediatric Anesthesia, \\ Department of Anesthesiology \\ and Critical Care Medicine, Johns \\ Hopkins Hospital and Johns Hopkins \\ University, School of Medicine, \\ Baltimore, Maryland, USA
}

Video abstract

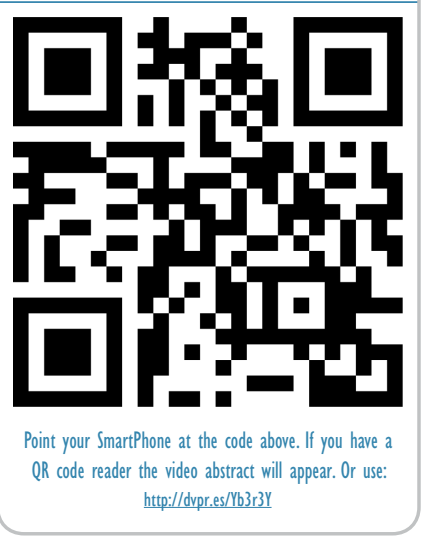

Correspondence: Sabine Kost-Byerly Johns Hopkins Charlotte Bloomberg Children's Center, 1800 Orleans Street Suite 6321, Baltimore, Maryland 2I 287, USA

$\mathrm{Tel}+\mathrm{I} 4 \mathrm{I} 09557610$

Fax + | 4| 0502 53।2

Email skbyerly@jhmi.edu
Abstract: The exstrophy-epispadias complex is a rare congenital malformation of the genitourinary system, abdominal wall muscles, and pelvic structures. Modern surgical repairs focus on reconstruction of the bladder and its adjacent structures, with the goal of achieving urinary continence, a satisfactory cosmetic result, and a high quality of life. Complex surgery in neonates and young children, as well as a prolonged postoperative course require close collaboration between surgeons, anesthesiologists, intensivists, pediatricians, and an experienced nursing staff. This article will review the spectrum of bladder exstrophy anomalies, the surgical repair, and the perioperative interdisciplinary management.

Keywords: bladder exstrophy, infant, newborn, surgery, anesthesia

\section{Introduction}

Bladder exstrophy is a rare congenital malformation of the genitourinary system with an estimated incidence of approximately one per 50,000 live births. ${ }^{1}$ Most patients with this disorder will undergo multiple corrective surgical procedures in order to achieve functionally and cosmetically acceptable results. A well-established interdisciplinary team consisting of surgeons, anesthesiologists, pediatricians, nutritionists, pharmacologists, nurses, and child life specialists are essential in providing the environment for successful outcomes.

While there are several surgical approaches, most bladder exstrophy repairs include closure of the bladder and abdominal wall, and an approximation of the pelvic rami. Postoperatively, children are immobilized in order to promote healing and to maintain pelvic ring integrity. Immobilization in traction may continue for several weeks postoperatively. During this time, pain management, nutritional support, and meticulous nursing care for osteotomy pin sites, surgical drains and stents, and skin integrity become a focus.

Bladder exstrophy closure is performed in three distinct groups of patients, each posing unique challenges during the perioperative period: newborns for initial closure, slightly older infants with small bladder templates for delayed closure, and finally, children with failed initial closures for repeat repairs. Neonates and infants have a higher risk of complications due to surgery and anesthesia than older children. Newborn patients transitioning from fetal circulatory system to an extrauterine one are vulnerable to intraoperative hemodynamic disturbances resulting in acidosis and profound hypoxia. Due to the immaturity of the neonatal brain, the child is more vulnerable to respiratory depression in response to sedatives and opioid analgesia. Pelvic osteotomies to improve the approximation of the pelvic rami are recommended for patients beyond 
5 days of life, but they increase the risk of blood loss, which is more concerning in young patients with limited blood volume. Increased intraoperative cardiovascular monitoring may be necessary. Finally, repeat closures in patients with failure of an initial repair are complex undertakings lasting well beyond the immediate surgical repairs. Maintaining postoperative immobility in traction for several weeks in order to promote the healing of osteotomies and abdominal suture lines poses a challenge in active toddlers. Careful postoperative analgesic and sedation management can make this process tolerable for patients and their families.

Postoperative analgesic management requires a multimodal approach considering the unique needs of each patient. As systemic opioids can be associated with respiratory depression, epidural anesthesia with continuous local anesthetic infusions have been advocated for neonates and older children in order to provide postoperative analgesia for procedures of the lower abdomen and lower extremities. Epidural analgesic infusion may also provide a mild motor block, which is desirable for children requiring prolonged immobilization and orthopedic traction. While epidural analgesia may decrease painful bladder spasms, the dual innervations of the bladder may require supplementation with spasmolytics or muscle relaxants.

Prolonged surgery, anesthesia, and need for multimodal postoperative analgesic and sedation management in young children results in increased cardiorespiratory monitoring needs, at least within the first few postoperative days. This can be accomplished either in an intensive care unit or in an intermediate care unit with increased monitoring capability. Continuous epidural infusions in young infants can be managed on the regular ward, as long as appropriate monitoring and experienced nursing staff are available.

Postoperatively, patients may require several days before bowel function is restored. In order to avoid abdominal distention and undue stress on delicate suture lines, surgeons may opt to wait additional days before resuming enteral feedings in their patients. Once patients are allowed to resume enteral feeds, consumed volumes should be assessed carefully. This can be achieved either by measuring volumes or by spending time with children who are breastfeeding. Placing newborns with their traction into large adult beds can facilitate successful breastfeeding as the mother is able to position herself next to the child. Supplementation via nasogastric tubes is indicated if the child is not taking adequate volumes. Consultation and close working relationships with a pediatric hospitalist or hospital nutritionist is helpful in these situations.
Nursing staff are the frontline providers and essential partners in the team approach required for successful management of bladder exstrophy patients. Experienced staff will know how to care for surgical stents, drains, and pins, assess pain and discomfort, and provide an environment of calm and comfort for patients and parents. Clustering essential nursing care and avoiding undue disturbance of the patient is desirable in order to avoid agitation. Distraction of the patient with soothing music and other calm activities is helpful, although attention span in infants and toddlers is limited.

While a team approach is essential for the complex perioperative needs of these patients, it is also important for caring for the child's family. Long hospitalizations can be draining, both emotionally and financially. For the lay parent, the significance of minor complications can be difficult to comprehend leaving the impression of a rollercoaster ride, while the medical team may perceive the same hospitalization as having a very smooth course. Family members should be encouraged to take time out for themselves. Increased parental anxiety can be sensed by the child and will increase agitation. Calm and collected parents are medical teams' best friends.

\section{Etiology and pathogenesis}

The exstrophy-epispadias complex is a rare congenital malformation of the genitourinary system that has an estimated incidence of approximately one per 50,000 live births. ${ }^{1}$ Approximately twice as many males are affected. ${ }^{2}$ Additionally, white infants are significantly more likely to present with the complex than nonwhite infants. ${ }^{1}$

The exstrophy-epispadias complex represents a severe midline abdominal birth defect that causes wide separation of the pubic symphysis, an abdominal wall defect, and an anterior-positioned open bladder and urethra. Epispadias and classical bladder exstrophy may occur in isolation, but cloacal exstrophy often carries with it various other malformations of the gastrointestinal tract, skeletal system, and neurological system. ${ }^{3}$ The bladder remains open on the abdominal wall in both classical bladder exstrophy and cloacal exstrophy, while the bladder is found to be closed and in a normal position among children born with isolated epispadias. The majority of patients with this complex have classical bladder exstrophy and an open bladder.

During development, the cloacal membrane is situated at the caudal end of a trilaminar blastoderm. Mesenchymal ingrowth between the layers of ectoderm and endoderm leads to formation of the lower abdominal musculature and pelvic bones. The exstrophy-epispadias complex is felt to be a 
consequence of premature rupture of the cloacal membrane. ${ }^{4}$ The timing and location of the defect determine if the fetus will develop cloacal exstrophy, classical bladder exstrophy, or epispadias. ${ }^{5,6}$ It has been postulated that earlier rupture of the cloacal membrane that occurs before the urorectal septum has fused with the membrane leads to cloacal exstrophy. Others have suggested that mesodermal migration may be halted by mechanical obstruction or altered mesenchymal cell populations. ${ }^{8}$ Another possibility is that the birth defect is a consequence of failure of the bony pelvis to rotate properly during development, preventing midline structures to fuse in the midline and bladder herniation. ${ }^{9}$

\section{Spectrum of anomalies Pelvic bones}

Patients with the exstrophy-epispadias complex have a widened pubic symphysis due to malrotation of the pelvic innominate bones. Additionally, patients with classical bladder exstrophy are found to have external rotation of both the anterior and posterior pelvis, retroversion of the acetabulum, and shortening of the pubic rami. ${ }^{10}$ Compared to persons without classical bladder exstrophy, these patients have larger sacroiliac joint angles, a more inferiorly rotated pelvis, and a larger sacrum. ${ }^{11}$ In addition to leaving the child with a widened pubic symphysis, these pelvic deformities lead many children to have shortening of the penis and a waddling gait.

\section{Spine}

Additional spinal and orthopedic abnormalities can be seen with the exstrophy-epispadias complex. A minority of patients with classical bladder exstrophy have been noted to have spinal abnormalities, such as spina bifida occulta, scoliosis, and hemivertebrae. ${ }^{12}$ Most of these findings are asymptomatic and of little consequence to the patient. However, nearly all patients with cloacal exstrophy suffer from various neurological deficits, including neural tube defects, vertebral anomalies, and tethered cord. ${ }^{13}$ Oftentimes, urinary and bowel incontinence are further complicated by a neurogenic deficit in these patients. Skeletal and limb anomalies, such as clubfoot, severe tibial malformations, and congenital hip dislocations, are also common among children with cloacal exstrophy. ${ }^{3}$

\section{Pelvic floor musculature}

Patients with bladder exstrophy also have an abnormal pelvic floor. The levator ani muscle group is positioned more posterior, and the anus is found to be more anterior. Additionally, the levators are rotated outward and flattened, yielding a much flatter puborectalis sling with an anterior positioned bladder. ${ }^{11}$ Abnormalities of the pelvic floor also predispose female patients to uterine prolapse. ${ }^{14}$

\section{Abdominal wall}

Perhaps the most profound anomaly is the defect in the ventral abdominal wall fascia, resulting in an open and anterior positioned bladder and urethra. The band of tissue between the widened pubic tubercles, known as the intersymphyseal band, represents the urogenital diaphragm, and is where the anterior sheath of the rectus muscle inserts posterior to the bladder neck and urethra. The umbilicus is typically situated in a more caudal position and represents the superior limit of the abdominal wall defect. Occasionally, a small omphalocele may be present in patients with classical bladder exstrophy. However, with cloacal exstrophy, patients will usually have a large omphalocele, and the two bladder plates will be separated by a midline piece of ileum. ${ }^{3}$

\section{Anorectal anomalies}

The anus is usually found anterior to a short and broad perineum with an anteriorly displaced anal sphincter. The distorted deep pelvic floor anatomy and sphincter displacement can predispose the child to fecal incontinence and other colorectal anomalies, including imperforate anus, rectal stenosis, and rectal prolapse. ${ }^{15}$ Patients with cloacal exstrophy tend to have a higher incidence of associated gastrointestinal tract abnormalities, including a rudimentary hindgut, malrotation, and short bowel. , $^{3,16}$

\section{Genitalia}

Males with the exstrophy-epispadias complex are born with a profound genital defect. In addition to dorsal opening in the urethra resulting in epispadias, the corporal bodies have been found to be significantly smaller in length and caliber when compared to age-matched controls. ${ }^{17}$ Furthermore, diastasis of the pubic symphysis, dorsal chordee, and a shortened urethral groove all give the appearance that the penis looks smaller. Females are known to have a shorter vagina, stenotic vaginal orifice, bifid clitoris, and divergent labia. ${ }^{18}$ In cloacal exstrophy, the phallus is separated into two halves and may be of unequal size. ${ }^{3}$

\section{Bladder}

The exstrophied bladder and urethra are open anteriorly. In some patients, the bladder has a small capacity and is covered with epithelial polyps. ${ }^{19}$ Furthermore, some bladders have poor compliance and detrusor instability. ${ }^{20}$ Since the bladder 
is found to be in an anterior position, the ureters enter the bladder from an abnormal angle, leading to vesicoureteral reflux in all children with exstrophic bladders. ${ }^{21}$ Other upper urinary tract and renal anomalies, such as horseshoe kidney, appear to be more common among children with the exstrophy-epispadias complex. ${ }^{22}$

\section{Diagnosis and evaluation}

Bladder exstrophy can be diagnosed during prenatal development with fetal ultrasonography between the 15 th and 32 nd week of pregnancy. ${ }^{23}$ Criteria for diagnosis include absence of bladder filling, low-set umbilicus, widening pubic rami, small genitalia, and lower abdominal mass that increases throughout the duration of pregnancy. ${ }^{24}$ Prenatal diagnosis allows for proper counseling of the parents regarding the potential implications of the child's diagnosis. Furthermore, early detection allows for arrangement of the delivery to take place in a specialized center for exstrophy where immediate repair of the birth defect can be performed by a multidisciplinary team of individuals that have experience with the management of this disease.

Despite this, only $25 \%$ of patients who are born with the exstrophy-epispadias complex were diagnosed during the prenatal period. ${ }^{25}$ When a child is born with exstrophy, clinical diagnosis is readily apparent given the obvious birth defect. Routine laboratory studies should be obtained along with renal ultrasonography. Proper neonatal evaluation, including thorough cardiac and pulmonary assessments, should be made shortly after birth. Patients with cloacal exstrophy should undergo spinal ultrasonography and neurosurgical evaluation. The bladder and bowel segments should be covered with a nonadherent dressing, such as plastic wrap, and kept clean with saline washes at each diaper change. Evaluation under anesthesia is helpful to evaluate the patient's bladder and formulate a management strategy once stabilized. Further consideration to transferring the child to a center with exstrophy management experience should be considered only after the patient has been stabilized and the parents have been properly counseled. Patients who are managed in high-volume centers may have a lower rate of postoperative mortality. ${ }^{26}$

\section{Prognosis}

Historically, children with exstrophy died of renal failure prior to reaching the age of adulthood. Initial management strategies often resulted in cystectomy; however, current practice allows for bladder preservation in nearly every child. Application of the modern staged repair of exstrophy
(MSRE) as first described by Jeffs ${ }^{27}$ has resulted in a shift of focus from survival to quality of life.

Perhaps the single most important focus of bladder exstrophy repair is urinary continence. While the definition of urinary continence widely varies, approximately $70 \%$ to $80 \%$ of children will become continent through the urethra with modern reconstructive techniques. ${ }^{28,29}$ However, intermittent urethral catheterization or urinary diversion is sometimes necessary to achieve dryness, especially among patients with cloacal exstrophy. ${ }^{30}$ The risk of urinary incontinence and the need for urinary diversion are both increased by failed initial closure and poor bladder growth. ${ }^{31,32}$

\section{Overview of the current treatment options for bladder exstrophy}

Repair of bladder exstrophy remains challenging due to the complexity and relative infrequency of the disease. While many approaches to exstrophy repair exist, nearly all children will require closure of the bladder and abdominal wall, repair of epispadias, ureteral reimplantation, and bladder neck repair. Many children also undergo pelvic osteotomies to assist with abdominal wall closure, along with a period of postoperative pelvic and lower extremity immobilization. Further continence procedures and genital surgeries are also common. Children with cloacal exstrophy tend to require more surgeries given the various additional organ systems affected.

\section{Modern staged repair of bladder exstrophy}

The first staged approach to bladder exstrophy repair described by Jeffs ${ }^{27}$ has been modified over the past 30 years to become the MSRE. This approach advocates for the primary closure of the abdominal wall and bladder during the newborn period when possible. ${ }^{3}$ If the bladder template is small or covered with polyps, primary closure may be delayed until the bladder reaches suitable size for closure. ${ }^{19}$ The goal of primary closure is to place the bladder deep within the pelvis, leaving the child with only an epispadias of the penile shaft. In most cases, bilateral iliac and transverse innominate pelvic osteotomies are performed unless the child is less than 72 hours old and the pelvis is found to be malleable enough to close. Early primary closure of the bladder has been associated with decreased overall costs, decreased inflammation and fibrosis of the bladder, improved bladder growth, and decreased need for urinary diversion. ${ }^{33-38}$

In males, a modified Cantwell-Ransley epispadias repair is typically performed between 6 and 12 months of age if 
the urethral groove has adequate length after testosterone stimulation. In cases where primary closure is delayed past the newborn period, the closure and epispadias repair may be performed at the same time. Following epispadias repair, the bladder capacity is measured annually with a cystogram under anesthesia. Once the child has a functional bladder with a capacity of at least $85 \mathrm{~mL}$ and is of an age when continence is desired (typically 4 to 5 years old), a modified YoungDees-Leadbetter bladder neck reconstruction is performed. At this time, the ureters are usually reimplanted. Children who are unable to achieve a capacity adequate for bladder neck repair or who fail to achieve a reasonable interval of dryness after bladder neck repair may require augmentation cystoplasty and continent urinary diversion. Long-term follow-up among patients with classical bladder exstrophy treated with this approach demonstrated that $70 \%$ of children will be dry and voiding through the urethra with a minimal complication rate. ${ }^{29}$

\section{Complete primary repair of exstrophy}

First described by Grady and Mitchell, ${ }^{39}$ the complete primary repair of exstrophy is an approach that combines primary closure of the abdomen and bladder with epispadias repair. Proponents of this approach suggest that the complete primary repair of exstrophy allows for a one-stage repair and stimulates early bladder growth. The epispadias repair is accomplished by dissecting the urethral plate from the corporal bodies, a technique known as "penile disassembly." 40 While this approach reduces the number of planned surgeries, many children require further surgery for resulting hypospadias, ureteral reimplantation, or failed primary closure. ${ }^{39,41}$ Furthermore, complications such as wound dehiscence, bladder prolapse, vesicocutaneous fistula, and penile loss have been reported. ${ }^{42-44}$ Long-term urinary continence with this approach has been reported to achieve similar success rates to MSRE. ${ }^{45,46}$ However, recent data suggest that many of these patients require further surgery to achieve durable urinary continence. ${ }^{42}$

\section{Erlangen repair}

Used mostly in Europe, the Erlangen approach is truly a complete one-stage repair. Primary closure is delayed until the child is approximately 8 to 10 weeks of age. Bladder closure, epispadias repair, bladder neck repair, ureteral reimplantation, and pelvic osteotomies are all performed during the same surgery. Delaying surgery allows time for the infant to be stabilized and grow. Continence rates have been reported to be similar to MSRE. ${ }^{28}$

\section{Kelly repair}

The Kelly approach is an alternative staged repair that was popularized in Australia. Instead of using pelvic osteotomies, a tension free closure is accomplished through radical soft tissue mobilization of the urogenital diaphragm muscles from their periosteal attachments to the pelvic sidewall. Long-term continence results are similar to MSRE; however, failure to approximate the pubic symphysis may leave the child with abnormal appearance of the lower abdominal wall. ${ }^{47}$

\section{Warsaw approach}

The Warsaw approach is a two-stage approach that involves early abdominal wall and bladder closure with proper lower extremity and pelvic immobilization. A modified CantwellRansley epispadias repair is delayed until the modified Young-Dees-Leadbetter bladder neck repair is performed at an age when the child desires continence. This approach allows for better visualization of the bladder neck at the time of repair and provides a straighter posterior urethra and bladder neck, allowing for easier catheterization and cystoscopy. ${ }^{48}$

\section{Pelvic osteotomies and immobilization}

While invasive, pelvic osteotomies are associated with improved outcomes following the closure of bladder exstrophy. ${ }^{49}$ Pelvic osteotomy performed at the time of primary closure allows for tension-free approximation of the pubic symphysis, places the bladder and urethra deep within the pelvis, and brings the pelvic floor muscles in the midline. If the child is to be closed within 72 hours of birth and the pelvis is malleable, pelvic osteotomies may be avoided. The most frequently used osteotomies involve a combination of bilateral anterior innominate and vertical iliac osteotomies. Compared to the use of posterior iliac osteotomies, transverse anterior innominate osteotomies, or pubic ramotomies, this approach has been shown to decrease the rate of abdominal dehiscence and bladder prolapse. ${ }^{50}$

At the time of the osteotomy, fixator pins can be placed into the pelvic fragments. Postoperatively, these pins can be used to keep the pelvis fixed with external fixators for 4 to 6 weeks. Plain film radiographs of the pelvis are obtained approximately 7 to 10 days following surgery to evaluate the pelvic approximation. If pubic diastasis is discovered to develop during the postoperative period, the external fixator can be used to gradually reapproximate the pubic symphysis. The fixator and pins can be removed under light sedation in approximately 6 to 8 weeks when good callous formation 
is seen on radiographs. The pelvis is further stabilized by immobilization of the lower extremities for approximately 4 weeks after primary closure. This is best accomplished with the use of modified Buck's traction, where the child's legs are placed on longitudinal traction. If the child does not undergo osteotomy, pelvic immobilization can be best accomplished with the use of modified Bryant's traction, where traction is applied to the lower extremities with the hips placed into 90 degrees of flexion.

Alternative methods of postoperative pelvic and lower extremity immobilization exist that can be employed with or without the use of osteotomies. Precluding the need for external fixators and lower extremity traction, a spica cast can be used to immobilize the child's pelvis for 4 weeks with comparable success and complication rates. ${ }^{51}$ This method of immobilization tends to be easier to care for once the child leaves the hospital; however, postoperative adjustment of pelvic tension cannot be accomplished as with external fixators. A less secure method of immobilizing the lower extremities can be accomplished by "mummy wrapping" the child's legs. One large retrospective study found that both spica casting and "mummy wrapping" were associated with lower overall success of the primary closure, and higher rates of skin breakdown compared to patients who underwent osteotomy with modified Buck's traction or without osteotomy and modified Bryant's traction. ${ }^{49}$

\section{Perioperative anesthetic, analgesic, and sedation management}

After induction of anesthesia, an epidural catheter is placed. The dermatomes to be covered during surgery reach from the low thorax to the sacrum, thus requiring a relatively large spread of local anesthetic. Catheters can be placed in the sacral caudal region or in the lumbar one. Insertion at the caudal site requires advancement of the tip of the catheter to the lumbar region. In young infants, blind advancement of the catheter can be achieved in two-thirds of the patients. ${ }^{52}$ Correct positioning can be confirmed with a "whiff" of Omnipaque $^{\mathrm{TM}} 180$ (GE HealthCare, Inc., Princeton, NJ, USA) injected into the catheter. Special catheters for placement at the desired location are available such as the Tsui stimulating or electrocardiography catheter. ${ }^{53,54}$

Teaching institutions frequently prefer the caudal insertion site, as the risk of injury to the spinal cord is remote due to the more caudate termination of the cord even in young infants. Unfortunately, compared to the lumbar site, the caudal insertion site is associated with an increased risk of catheter colonization after 3 days. ${ }^{55}$ Even at the lumbar site, maintaining the catheter for several weeks is not advised unless the catheter is tunneled.

In order to easily tunnel a 20 gauge epidural catheter, it is initially inserted caudally through an 18 gauge, 2 inch Crawford needle (caudal epidural tray number 15752-20, Portex, Inc, Keene, NH, USA), and advanced to the desired position. Then a 22 gauge spinal needle is inserted at exactly the same entry site as the Crawford needle and advanced under the skin caudate of the superior iliac crest where it emerges. The spinal needle becomes a guide over which a 17 gauge Tuohy needle without its stylette is guided until it emerges at the primary needle insertion site. The spinal needle and Crawford needle are then removed. The catheter is fed through the Tuohy needle. Finally, the Tuohy needle is withdrawn and the length of the catheter is gently pulled at its exit site, caudate of the iliac crest, until it lies flat under the skin at the initial insertion site. Steri-Strips ${ }^{\circledR}$ (3M Health Care, Saint Paul, MN, USA) and transparent adhesive dressings are applied to the initial insertion site and the catheter exit site. The catheter is then injected with local anesthetic. While the dressing at the exit site is changed every 5 days, the one at the initial insertion site can be safely removed within a few days, as skin will completely seal over the catheter. In case of a lumbar epidural catheter placement, a Tuohy needle takes the place of the Crawford needle.

Postoperatively, continuous infusions of local anesthetic are infused. In neonates, administration of lidocaine $1 \mathrm{mg} / \mathrm{mL}$ at a rate no higher than $0.8 \mathrm{mg} / \mathrm{kg} /$ hour is recommended. ${ }^{56}$ While bupivacaine or ropivacaine are frequently administered in epidural infusions, no information concerning a safe dose is available for neonates and young infants. Infusions of $0.2 \mathrm{mg} /$ $\mathrm{kg} /$ hour of bupivacaine were associated with rising serum levels after 2 days of epidural infusions in the youngest patients. ${ }^{57}$

Whereas assessment of serum bupivacaine or ropivacaine levels is primarily available to research laboratories, serum lidocaine levels are frequently measured by in-house laboratories as lidocaine remains a therapeutic agent for the management of cardiac patients. Serial once or twice a day measurement of lidocaine during the first few days can help minimize the risk of local anesthetic systemic toxicity. In older patients, bupivacaine or ropivacaine can be infused up to $0.04 \mathrm{mg} / \mathrm{kg} /$ hour. $^{58}$

For synergistic effects and improved analgesia, additives can be combined with local anesthetics during epidural infusion. Opioids, such as fentanyl or hydromorphone, and clonidine are most commonly used. Active toddlers benefit from the addition of clonidine as it is associated with sedation, a desired effect in this population. ${ }^{59}$ 
Depending on the needs of the child, other enteral and parenteral medications may be required for additional analgesia or sedation. These include opioids, benzodiazepines, diphenhydramine, and barbiturates. All of these medications can be associated with tolerance and withdrawal should they be stopped suddenly after a longer period of time. Thus, gradual weaning of medications is advised after usage for more than 7 to 10 days.

\section{Implications for enhanced patient care and improved quality of life}

Successful primary closure of the bladder is the single most important predictor of long-term bladder growth and voided continence. ${ }^{31,36}$ Primary closure of bladder exstrophy tends to fail during the immediate postoperative period by one of the following modes: wound dehiscence, bladder prolapse, bladder outlet obstruction, or vesicocutaneous fistula. ${ }^{44,60}$ Proper immobilization of the pelvis as described above, along with adequate sedation and pain control, have been shown to decrease the rate of postoperative complications and failure of closure. ${ }^{49}$

All patients should be maintained on antimicrobial prophylaxis following primary closure. In addition to the high rate of vesicoureteral reflux associated with the exstrophyepispadias complex, various tubes, stents, and drains from the urinary tract and pelvic fixator pins all represent routes of potential infections of the urine, bone, or wound that can lead to potential pyelonephritis, wound dehiscence, and further need for surgical intervention. ${ }^{42}$ It is imperative that the wound remains dry and free from tension. In addition to pelvic immobilization, the bladder and kidneys are drained with a suprapubic catheter and ureteral stents for the duration of immobilization to prevent bladder distention, urinary obstruction, or spillage onto the wound. Additionally, the wound can be kept dry with the use of a suction drain. ${ }^{61}$ After pelvic immobilization and ureteral stents have been removed, the urethra and bladder neck can be calibrated with a urethral sound to ensure patency before the suprapubic tube is removed.

In one study, the mean length of stay among patients who underwent bladder closure was approximately 30 days. ${ }^{26}$ Prior to return of bowel function, a nasogastric tube is left in place to decompress the bowels and reduce tension on the wound. Total parenteral nutrition may be implemented to maintain proper caloric intake. In patients with cloacal exstrophy, bowel function may not return for 2 weeks. ${ }^{62}$ Enteral tube feeds may be initiated once bowel function has returned.

\section{Conclusion}

Management of bladder exstrophy, a rare congenital malformation with previously devastating effects on function and quality of life, has significantly changed over the last few decades. Perioperative management now includes bladder closure, pelvic osteotomies - except for the youngest patients postoperative traction and immobilization, pain and sedation management, nutritional management, and advanced pediatric nursing care. A team of pediatric urologists, orthopedic surgeons, anesthesiologists, pediatricians, pediatric nursing staff, and other hospital staff working together can provide the child with the best chance for a functional and cosmetic result.

\section{Disclosure}

The authors report no conflicts of interest in this work.

\section{References}

1. Nelson CP, Dunn RL, Wei JT. Contemporary epidemiology of bladder exstrophy in the United States. J Urol. 2005;173(5):1728-1731.

2. Gambhir L, Höller T, Müller M, et al. Epidemiological survey of 214 families with bladder exstrophy-epispadias complex. J Urol. 2008;179(4):1539-1543.

3. Diamond DA, Jeffs RD. Cloacal exstrophy: a 22-year experience. J Urol. 1985;133(5):779-782.

4. Ambrose SS, O'Brien DP 3rd. Surgical embryology of the exstrophyepispadias complex. Surg Clin North Am. 1974;54(6):1379-1390.

5. Muecke EC. The role of the cloacal membrane in exstrophy: the first successful experimental study. J Urol. 1964;92:659-667.

6. Martínez-Frías ML, Bermejo E, Rodríguez-Pinilla E, Frías JL. Exstrophy of the cloaca and exstrophy of the bladder: two different expressions of a primary developmental field defect. Am J Med Genet. 2001;99(4):261-269.

7. Russell LJ, Weaver DD, Bull MJ. The axial mesodermal dysplasia spectrum. Pediatrics. 1981;67(2):176-182.

8. Vermeij-Keers C, Hartwig NG, van der Werff JF. Embryonic development of the ventral body wall and its congenital malformations. Semin Pediatr Surg. 1996;5(2):82-89.

9. Beaudoin S, Barbet P, Bargy F. Pelvic development in the rabbit embryo: implications in the organogenesis of bladder exstrophy. Anat Embryol (Berl). 2004;208(6):425-430.

10. Sponseller PD, Bisson LJ, Gearhart JP, Jeffs RD, Magid D, Fishman E. The anatomy of the pelvis in the exstrophy complex. J Bone Joint Surg Am. 1995;77(2):177-189.

11. Stec AA, Pannu HK, Tadros YE, et al. Evaluation of the bony pelvis in classic bladder exstrophy by using 3D-CT: further insights. Urology. 2001;58(6):1030-1035.

12. Cadeddu JA, Benson JE, Silver RI, Lakshmanan Y, Jeffs RD, Gearhart JP. Spinal abnormalities in classic bladder exstrophy. $\mathrm{Br} J$ Urol. 1997;79(6):975-978.

13. McLaughlin KP, Rink RC, Kalsbeck JE, et al. Cloacal exstrophy: the neurological implications. J Urol. 1995;154(2 Pt 2):782-784.

14. Woodhouse CR, Hinsch R. The anatomy and reconstruction of the adult female genitalia in classical exstrophy. Br J Urol. 1997;79(4): 618-622.

15. Stec AA, Baradaran N, Tran C, Gearhart JP. Colorectal anomalies in patients with classic bladder exstrophy. J Pediatr Surg. 2011;46(9):1790-1793.

16. Hurwitz RS, Manzoni GA, Ransley PG, Stephens FD. Cloacal exstrophy: a report of 34 cases. J Urol. 1987;138(4 Pt 2): 1060-1064. 
17. Silver RI, Yang A, Ben-Chaim J, Jeffs RD, Gearhart JP. Penile length in adulthood after exstrophy reconstruction. J Urol. 1997;157(3):999-1003.

18. Ansari MS, Gearhart JP, Cervellione RM, Sponseller PD. The application of pelvic osteotomy in adult female patients with exstrophy: applications and outcomes. BJU Int. 2011;108(6):908-912.

19. Novak TE, Lakshmanan Y, Frimberger D, Epstein JI, Gearhart JP. Polyps in the exstrophic bladder. A cause for concern? J Urol. 2005; 174(4 Pt 2):1522-1526; discussion 1526.

20. Diamond DA, Bauer SB, Dinlenc C, et al. Normal urodynamics in patients with bladder exstrophy: are they achievable? $J$ Urol. 1999;162(3 Pt 1):841-844; discussion 844-845.

21. Canning DA, Gearhart JP, Peppas DS, Jeffs RD. The cephalotrigonal reimplant in bladder neck reconstruction for patients with exstrophy or epispadias. J Urol. 1993;150(1):156-158.

22. Stec AA, Baradaran N, Gearhart JP. Congenital renal anomalies in patients with classic bladder exstrophy. Urology. 2012;79(1):207-209.

23. Ebert AK, Reutter H, Ludwig M, Rösch WH. The exstrophy-epispadias complex. Orphanet J Rare Dis. 2009;4:23.

24. Gearhart JP, Ben-Chaim J, Jeffs RD, Sanders RC. Criteria for the prenatal diagnosis of classic bladder exstrophy. Obstet Gynecol. 1995;85(6):961-964.

25. Goyal A, Fishwick J, Hurrell R, Cervellione RM, Dickson AP. Antenatal diagnosis of bladder/cloacal exstrophy: challenges and possible solutions. J Pediatr Urol. 2012;8(2):140-144.

26. Nelson CP, Bloom DA, Dunn RL, Wei JT. Bladder exstrophy in the newborn: a snapshot of contemporary practice patterns. Urology. 2005;66(2):411-415.

27. Jeffs RD. Functional closure of bladder exstrophy. Birth Defects Orig Artic Ser. 1977;13(5):171-173.

28. Ebert AK, Schott G, Bals-Pratsch M, Seifert B, Rösch WH. Long-term follow-up of male patients after reconstruction of the bladder-exstrophyepispadias complex: psychosocial status, continence, renal and genital function. J Pediatr Urol. 2010;6(1):6-10.

29. Baird AD, Nelson CP, Gearhart JP. Modern staged repair of bladder exstrophy: a contemporary series. J Pediatr Urol. 2007;3(4):311-315.

30. Mathews R. Achieving urinary continence in cloacal exstrophy. Semin Pediatr Surg. 2011;20(2):126-129.

31. Novak TE, Costello JP, Orosco R, Sponseller PD, Mack E, Gearhart JP. Failed exstrophy closure: management and outcome. J Pediatr Urol. 2010;6(4):381-384.

32. Chan DY, Jeffs RD, Gearhart JP. Determinants of continence in the bladder exstrophy population: predictors of success? Urology. 2001;57(4):774-777.

33. Nelson CP, North AC, Ward MK, Gearhart JP. Economic impact of failed or delayed primary repair of bladder exstrophy: differences in cost of hospitalization. J Urol. 2008;179(2):680-683.

34. Dodson JL, Surer I, Baker LA, Jeffs RD, Gearhart JP. The newborn exstrophy bladder inadequate for primary closure: evaluation, management and outcome. J Urol. 2001;165(5):1656-1659.

35. Gearhart JP, Ben-Chaim J, Sciortino C, Sponseller PD, Jeffs RD. The multiple reoperative bladder exstrophy closure: what affects the potential of the bladder? Urology. 1996;47(2):240-243.

36. Baradaran N, Cervellione RM, Orosco R, Trock BJ, Mathews RI, Gearhart JP. Effect of failed initial closure on bladder growth in children with bladder exstrophy. J Urol. 2011;186(4):1450-1454.

37. Oesterling JE, Jeffs RD. The importance of a successful initial bladder closure in the surgical management of classical bladder exstrophy: analysis of 144 patients treated at the Johns Hopkins Hospital between 1975 and 1985. J Urol. 1987;137(2):258-262.

38. McMahon DR, Cain MP, Husmann DA, Kramer SA. Vesical neck reconstruction in patients with the exstrophy-epispadias complex. J Urol. 1996;155(4):1411-1413.

39. Grady RW, Mitchell ME. Complete primary repair of exstrophy. J Urol. 1999;162(4):1415-1420.
40. Mitchell ME, Bägli DJ. Complete penile disassembly for epispadias repair: the Mitchell technique. J Urol. 1996;155(1):300-304.

41. El-Sherbiny MT, Hafez AT. Complete repair of bladder exstrophy in boys: can hypospadias be avoided? Eur Urol. 2005;47(5):691-694.

42. Schaeffer AJ, Stec AA, Purves JT, Cervellione RM, Nelson CP, Gearhart JP. Complete primary repair of bladder exstrophy: a single institution referral experience. J Urol. 2011;186(3):1041-1046.

43. Husmann DA, Gearhart JP. Loss of the penile glans and/or corpora following primary repair of bladder exstrophy using the complete penile disassembly technique. J Urol. 2004;172(4 Pt 2):1696-1700; discussion 1700-1701.

44. Alpert SA, Cheng EY, Kaplan WE, Snodgrass WT, Wilcox DT, Kropp BP. Bladder neck fistula after the complete primary repair of exstrophy: a multi-institutional experience. J Urol. 2005; 174(4 Pt 2):1687-1689; discussion 1689-1690.

45. Shnorhavorian M, Grady RW, Andersen A, Joyner BD, Mitchell ME. Long-term followup of complete primary repair of exstrophy: the Seattle experience. J Urol. 2008;180(Suppl 4):1615-1619; discussion 1619-1620.

46. Hammouda HM, Kotb H. Complete primary repair of bladder exstrophy: initial experience with 33 cases. J Urol. 2004;172(4 Pt 1):1441-1444; discussion 1444.

47. Jarzebowski AC, McMullin ND, Grover SR, Southwell BR, Hutson JM. The Kelly technique of bladder exstrophy repair: continence, cosmesis and pelvic organ prolapse outcomes. J Urol. 2009;182(Suppl 4): 1802-1806.

48. Baka-Jakubiak M. Combined bladder neck, urethral and penile reconstruction in boys with the exstrophy-epispadias complex. BJU Int. 2000;86(4):513-518.

49. Meldrum KK, Baird AD, Gearhart JP. Pelvic and extremity immobilization after bladder exstrophy closure: complications and impact on success. Urology. 2003;62(6):1109-1113.

50. Gearhart JP, Forschner DC, Jeffs RD, Ben-Chaim J, Sponseller PD. A combined vertical and horizontal pelvic osteotomy approach for primary and secondary repair of bladder exstrophy. J Urol. 1996;155(2): 689-693.

51. Arlen AM, Cooper CS, Morcuende J, Austin JC. Safety and efficacy of spica casts for immobilization following initial bladder closure in classic bladder exstrophy. J Pediatr Urol. 2011;7(4):456-459.

52. Valairucha S, Seefelder C, Houck CS. Thoracic epidural catheter placed by the caudal route in infants: the importance of radiographic confirmation. Pediatr Anaesth. 2002;12(5):424-428.

53. Tsui BC, Seal R, Koller J, Entwistle L, Haugen R, Kearney R. Thoracic epidural analgesia via the caudal approach in pediatric patients undergoing fundoplication using nerve stimulation guidance. Anesth Analg. 2001;93(5):1152-1155.

54. Tsui BC, Seal R, Koller J. Thoracic epidural catheter placement via the caudal approach in infants by using electrocardiographic guidance. Anesth Analg. 2002;95(2):326-330.

55. Kost-Byerly S, Tobin JR, Greenberg RS, Billett C, Zahurak M, Yaster M. Bacterial colonization and infection rates of continuous epidural catheters in children. Anesth Analg. 1998;86(4):712-716.

56. Kost-Byerly S, Jackson EV, Yaster M, Kozlowski LJ, Mathews RI, Gearhart JP. Perioperative anesthetic and analgesic management for newborn bladder exstrophy repair. J Ped Urol. 2008;4(4):280-285.

57. Larsson BA, Lönnquist PA, Olsson GL. Plasma concentrations of bupivacaine in neonates after continuous epidural infusions. Anesth Analg. 1997;84(3):501-505.

58. Bösenberg AT, Thomas J, Cronje L, et al. Pharmacokinetics and efficacy of ropivacaine for continuous epidural infusion in neonates and infants. Pediatr Anaesth. 2005;15(9):739-749.

59. Klamt JG, Garcia LV, Stocche MR, Meinberg AC. Epidural infusion of clonidine or clonidine plus ropivacaine for postoperative analgesia in children undergoing major abdominal surgery. $J$ Clin Anesth. 2003;15(7):510-514 
60. Novak TE. Failed exstrophy closure. Semin Pediatr Surg. 2011; 20(2):97-101.

61. Stec AA, Baradaran N, Schaeffer A, Gearhart JP, Matthews RI. The modern staged repair of classic bladder exstrophy: a detailed postoperative management strategy for primary bladder closure. J Pediatr Urol. 2011;8(5):549-555.
62. Davidoff AM, Hebra A, Balmer D, Templeton JM Jr, Schnaufer L. Management of the gastrointestinal tract and nutrition in patients with cloacal exstrophy. J Pediatr Surg. 1996;31(6):771-773.

Research and Reports in Urology

\section{Publish your work in this journal}

Research and Reports in Urology is an international, peer-reviewed, open access journal publishing original research, reports, editorials, reviews and commentaries on all aspects of adult and pediatric urology in the clinic and laboratory including the following topics: Pathology, pathophysiology of urological disease; Investigation and treatment of
Dovepress

urological disease; Pharmacology of drugs used for the treatment of urological disease. The manuscript management system is completely online and includes a very quick and fair peer-review system, which is all easy to use. Visit http://www.dovepress.com/testimonials.php to read real quotes from published authors.

Submit your manuscript here: http://www.dovepress.com/research-and-reports-in-urology-journal 